\title{
Therapeutic Management in Proximal Tracheal Rupture during Total Thyroidectomy
}

\author{
Victor J. Ovejero-Gomez ${ }^{*}$, M. V. Bermudez-Garcia' ${ }^{1}$, J. L. Lamfus-Prietoㄹ, T. Gallego-Bellido, \\ J. Villalba-Torre1, A. Ingelmo-Setien' ${ }^{1}$, J. M. Bajo-Arenas ${ }^{3}$ \\ ${ }^{1}$ Department of Surgery, Hospital Sierrallana, Cantabria, Spain \\ ${ }^{2}$ Department of Anaesthesiology, Hospital Sierrallana, Cantabria, Spain \\ ${ }^{3}$ Universidad Autónoma, Madrid, Spain \\ Email: vovejerohcas@msn.com
}

Received 10 April 2014; revised 9 May 2014; accepted 8 June 2014

Copyright (C) 2014 by authors and Scientific Research Publishing Inc. This work is licensed under the Creative Commons Attribution International License (CC BY). http://creativecommons.org/licenses/by/4.0/

(c) (i) Open Access

\begin{abstract}
Tracheal disruption is a life-threatening rare complication of total thyroidectomy that it should be prevented. The own-patient risk factors, procedure of tracheal intubation and a meticulous surgical technique are three main keys to keep in mind. Both medical and surgical management of this injury depends on its size, location and patient's symptoms although neither of them prevents late complications. An early diagnosis could improve with prognosis although it is mandatory to perform either respiratory functional or imaging study in order to assume its healing. When the tracheal laceration is diagnosed during the surgery, we should take care with a continuous monitoring of the patient's vital signs. A good oxygenation will be succeeded in high volume and low pressure with endotracheal tube distal to the lesion. We advice placing a tube drain near the disruption to prevent emphysema and an early extubation to avoid an ischaemic damage of the mucosa. A postoperative suspicion of tracheal rupture could demand reintubation with the patient in full relaxation and an examination by CT-scan or fiberscope before deciding a simple supportive therapy. We present our therapeutic experience in a female patient who suffered from tracheal injury during total thyroidectomy and describe a review of literature.
\end{abstract}

\section{Keywords}

Tracheal, Rupture, Iatrogenic, Thyroidectomy, Treatment

\footnotetext{
${ }^{*}$ Corresponding author.
} 


\section{Introduction}

Intraoperative tracheal rupture is infrequently reported, associated with a longitudinal laceration of the membranous part after intubation in most cases. Tracheal perforation during thyroidectomy is rarer still [1] because it is a very common and low-risk procedure. There are a few reports of its nonoperative treatment.

This iatrogenic trauma of the upper airways may be a potentially fatal injury needing urgent and aggressive management [2] due to immediate life-threatening complications in a context of typical symptoms of a rupture of the large airways and septic multiorgan failure.

We describe an iatrogenic proximal tracheal perforation during total thyroidectomy treated with direct suture repair and its post-surgical conservative treatment. According to the published literature, we discuss the importance of an early diagnosis, size and localization of the rupture for a successful management in this type of injury.

\section{Case Report}

A 46-year-old woman without past medical history, who complained of hyperthyroidism and dysnea secondary to respiratory compressive for three years, was admitted to our institution for elective treatment of hyperfunctioning nodular goiter (Figure 1(a) and Figure 1(b)).

The anesthetist reported a normal glottis on direct laryngoscopy and the intubation was performed with a 7.5mm cuffed single-lumen endotracheal tube. It was used a low-pressure baloon.

The cervical access was gained by an anterior collar incision without muscle division. Both lobes were mobilized with preservation of the recurrent laryngeal nerve in order to perform a total thyroidectomy. On Berry's ligament cutting with electrocautery, the endotracheal tube was looked protruding to the right anterior wall at the level of the second and third tracheal ring. There was no sign of inadequate ventilation. Neither the position of the endotracheal tube was exchanged nor the cuff deflated but the patient was ventilated using a high volume and low pressure.

Our patient underwent direct irreabsorbable suture repair of the injury (Figure 2(a)) and several Valsalva's manoeuvres were demanded to assume no leakage. We were placed a sucking drain in each surgical area and the cervical approach was closed.

She was taken to an intensive care unit and her vital signs stood stable. It was started an antibiotic treatment to prevent infectious complications. The endotracheal tube was removed in early post-operative and an air leak was demonstrated by a soft subcutaneous emphysema that it could be confirmed by a cervical x-ray. She was controlled with conservative treatment by the draining tubes on low-pressure suction. They were removed on the fifth day.

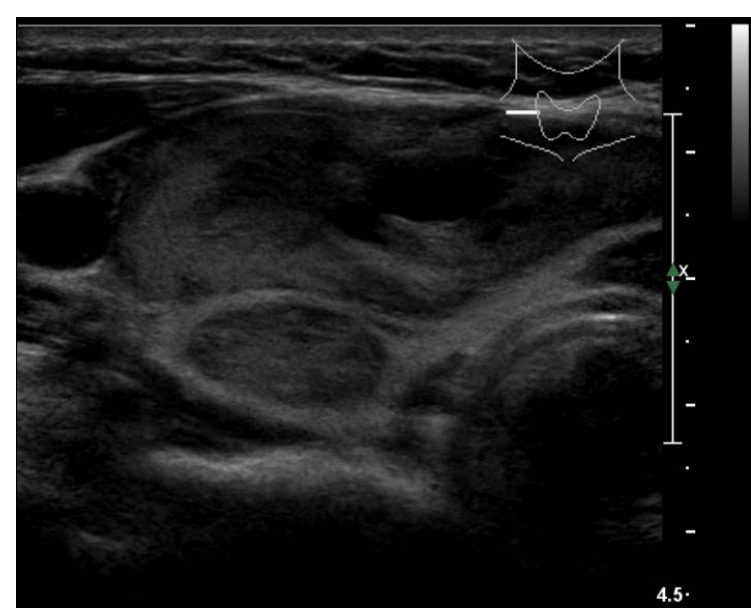

(a)

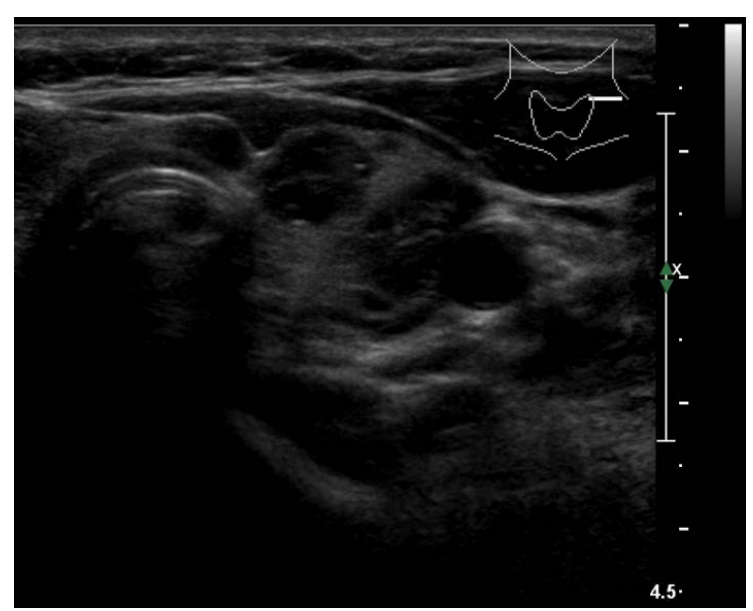

(b)

Figure 1. Cervical ultrasonography in the transverse plane showing an enlarged right thyroid lobe at the expense of two main nodules, one of them is anterior with cystic component and the other one posterior with a solid appearance (a) and multiple nodules with a cystic component, well-defined edges and peripherical hypoechogenic halo in the left thyroid lobe. It is worth mentioning a nodule located in the isthmus (b). 
There were no complications from the phoniatric and ventilatory point of view. She suffered from asymptomatic temporary hypocalcemia being discharged home at seven days and the antibiotherapy was continued for five days.

The follow-up was as outpatient. A fiberoptic bronchoscopy, performed on $15^{\text {th }}$ days, confirmed the complete closure on the laceration and no signs of tracheal stenosis were observed on the inspiratory-expiratory flow-volume curves.

The removed thyroid gland was reported as thyroid nodular hyperplasia and a healthy parathyroid gland (Figure 2(b)). The patient is asymptomatic at this moment.

\section{Discussion}

Iatrogenic tracheal rupture is associated to a high morbidity and mortality. It is an uncommon surgical complication, but well-described, caused by different mechanism [3] such as a difficult dissection between the trachea and the oesophagus, difficult or traumatic intubations, inappropriate use of a stylet, overinflation of the cuff with pressure exceeds $32 \mathrm{mmHg}$, intraoperative diffusion of nitric oxide into the cuff increasing its pressure and volume with values associated to ischemia or unsuspected anatomical variations.

Elder age, female patient assuming her membranous trachea less firm, diabetes mellitus, poor general condition, ventral localization and chronic corticotherapy are considered as risk factors [4].

Our patient's intubation was easy but an upper airway perforation happened intraoperatively during the technical procedure in spite of the surgical dissection was confined to the pretracheal fascia. Perhaps, a high temperature associated to the point of the electrocautery could be contributed to the injury.

We looked at the endotracheal tube through the tracheal wall although a gas leak was not detected because the cuff was probably serving as a plug to prevent it. The operating repair was performed direct suture using the same surgical time and cervical approach.

One of the main challenges for these patients is to support a spontaneous breathing as soon as possible. In our own opinion, certain keys could be share a successful outcome. An early diagnosis and the location of the injury are a cornerstone for the treatment [5]. Its discovery during the surgery could reduce the risk from infection in the cervical region and upper mediastinum, and permit to decide a surgical or medical management. According to some authors [6] [7], a laceration less than one third of the circumference of the trachea could be a good candidate to a conservative treatment and an operating repair would be more appropriate for the presence of a respiratory or circulatory failure. We preferred a simple sutured repair despite the extent of disruption was over two

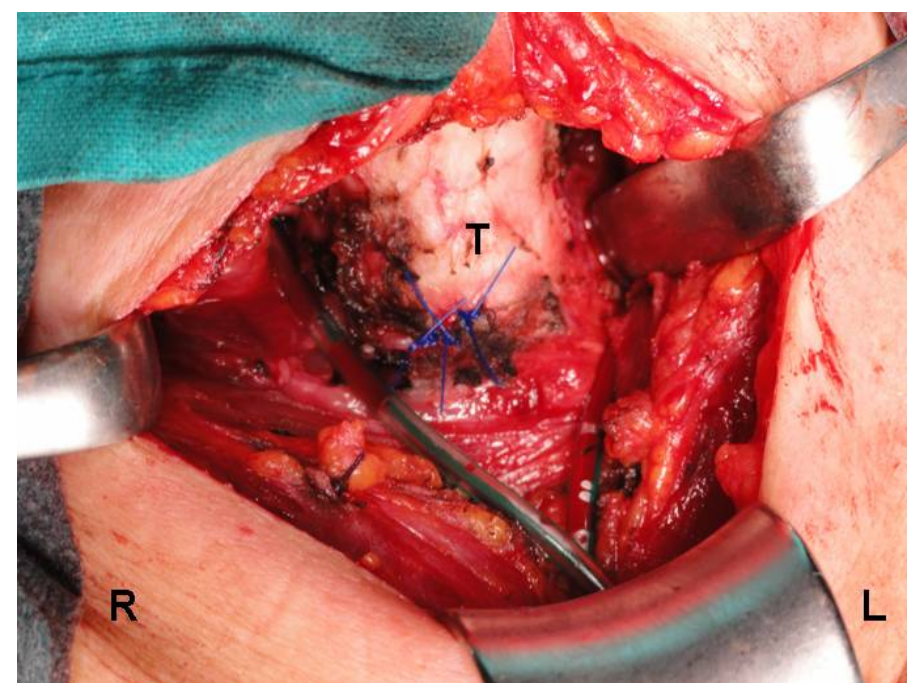

(a)

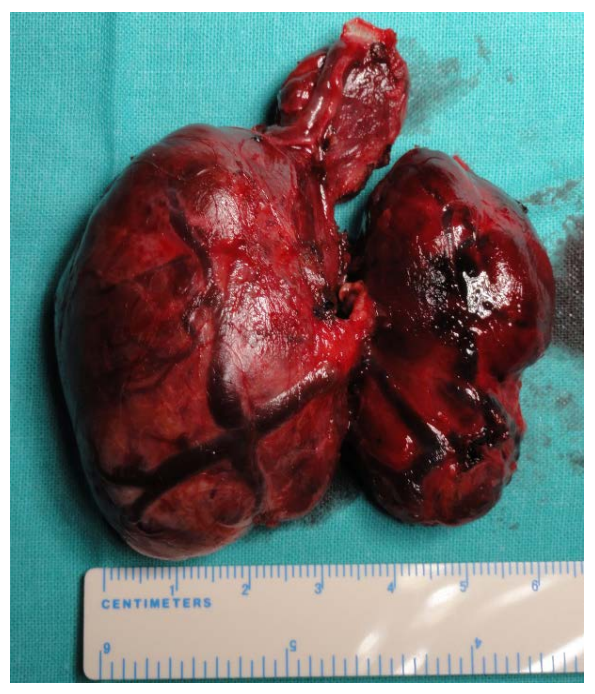

(b)

Figure 2. Exposure of the surgical field and thyroid specimen: (a) Detail of the surgical area showing the direct suture repair of the tracheal laceration with monofilament polypropylene 3-0 and two sucking drain tubes in the vicinity of the repaired injury (T: Trachea, R: Right side, L: Left side of the patient). (b) Total thyroidectomy for multinodular goiter with right predominance. It should be pointed out a large nodule in the pyramidal lobe. 
centimetres in right anterior wall of the trachea. The female patient was stable, using a low pressure ventilation and a local tube drainage to provide with an early extubation and prevent a failure of the healing because of distending weakened tissues by suction or a high positive pressure.

A second mode of airway support [8] could have been a high frequency ventilation because it allows a good intraoperative exposure of the disruption without the necessity for neither a high positive pressure nor inflation of the endotracheal tube cuff.

When the tracheal rupture is suspected during the thyroidectomy, an immediately fiber endoscopic exploration is the diagnostic procedure of choice [4] [9].

Other surgical procedures could be undertaken, depending on the size and location of the laceration, such as serosal grafts, for instance pericardium or pleura, or muscular patches from well-vascularized tissues [3] [10]. A right thoracotomy is not always needed to facilitate the approach but a tracheostomy should be considered to protect the operating repair in some cases.

Another therapeutic option seems to be a conservative treatment based on antibiotics and intubation with the cuff endotracheal tube distal to the lesion when the disruption is located in the upper third of the trachea and not to involve the whole thickness of the wall [11] [12].

On the other hand, this type of injury is sometimes diagnosed in the immediate postoperative period [4] [7] with subcutaneous emphysema or respiratory distress. The first diagnostic imaging study could be a chest $\mathrm{x}$-ray at reanimation theatre in quest of additional suspicious signs as pneumothorax or pneumomediastinum. A thoracic CT scan would be indicated to demonstrate mediastinal damages and identify the length of the tracheal laceration [13].

In these cases, reintubation should be done with the patient in full relaxation under fiberscopic control in order to make sure the distal placement of the tube.

When the lesion has been extended into carina or both main bronchi, an apneic oxygenation with selective intubation and a cardiopulmonary bypass could be required [14] [15].

A late interval from the onset of symptoms until the diagnosis is related with a poor prognosis. Both the conservative and surgical management should be taken into account as the potential risk of late consequences [9], above all a tracheal stenosis, and its difficult repair in the whole patients.

\section{References}

[1] Damrose, E.J. and Damrose, J.F. (2009) Delayed Tracheal Rupture Following Thyroidectomy. Auris Nasus Larynx, 36, 113-115. http://dx.doi.org/10.1016/j.anl.2008.03.007

[2] Vidal, M.C., Vázquez, E., Tercedor, A., Guzmán, E., Cuesta, P. and Galán, M. (2007) Conservative Management of the Airway Following Iatrogenic Rupture. Revista Espanola de Anestesiologia Reanimacion, 54, 246-249.

[3] Satyadas, T., Nasir, N., Erel, E. and Mudan, S.S. (2003) Iatrogenic Tracheal Rupture: A Novel Approach to Repair and a Review of the Literature. The Journal of Trauma, 54, 369-371. http://dx.doi.org/10.1097/01.TA.0000031940.95165.FE

[4] Moschini, V., Losappio, S., Dabrowska, D. and Iorno, V. (2006) Tracheal Rupture after Tracheal Intubation: Effectiveness of Conservative Treatment. Minerva Anestesiologica, 72, 1007-1012.

[5] Frova, G. and Sorbello, M. (2011) Iatrogenic Tracheobronchial Ruptures: The Debates Continues. Minerva Anestesiologica, 77, 1130-1133.

[6] D’Odemont, J.P., Pringot, J., Goncette, L., Goenen, M. and Rodenstein, D.O. (1991) Spontaneous Favorable Outcome of Tracheal Laceration. Chest, 99, 1290-1292. http://dx.doi.org/10.1378/chest.99.5.1290

[7] Kara, H., Bayir, A., Ahmet, A.K., Tufekci, N., Degirmenci, S. and Akinci, M. (2013) Tracheal Rupture Developing after Blunt Thoracic Trauma. Case Reports in Clinical Medicine, 2, 502-504.

[8] Barbetakis, N., Samanidis, G., Paliouras, D., Lafaras, C., Bischiniotis, T. and Tsilikas, C. (2008) Intraoperative Tracheal Reconstruction with Bovine Pericardial Patch Following Iatrogenic Rupture. Patient Safety in Surgery, 20, 4. http://dx.doi.org/10.1186/1754-9493-2-4

[9] Aydemir, B., Celik, S., Uncu, O., Tanrikulu, H. and Okay, T. (2013) Iatrogenic Tracheal Ruptures: Review of the Literature and Personal Experience on 11 Cases. Open Journal of Thoracic Surgery, 3, 130-134. http://dx.doi.org/10.4236/ojts.2013.34027

[10] Dreyfuss, D., Jackson, R.S., Coffin, L.H., Deane, R.S. and Shinozaki, T. (1986) High-Frequency Ventilation in the Management of Tracheal Trauma. The Journal of Trauma, 26, 287-289.

http://dx.doi.org/10.1097/00005373-198603000-00015 
[11] Jougon, J., Ballester, M., Choukroun, E., Dubrez, J., Reboul, G. and Velly, J.F. (2000) Conservative Treatment for Postintubation Tracheobronchial Rupture. The Annals of Thoracic Surgery, 69, 216-220. http://dx.doi.org/10.1016/S0003-4975(99)01129-7

[12] Deja, M., Menk, M., Heidenhain, C., Spies, C.D., Heymann, A., Weidemann, H., Branscheid, D., et al. (2011) Strategies for Diagnosis and Treatment of Iatrogenic Tracheal Ruptures. Minerva Anestesiologica, 77, 1155-1166.

[13] Shain, M., Anglade, D., Buchberger, M., Jankowski, A., Albaladejo, P. and Ferretti, G.R. (2012) Case Reports: Iatrogenic Bronchial Rupture Following the Use of Endotracheal Tube Introducers. Canadian Journal of Anaesthesia, 59, 963-967. http://dx.doi.org/10.1007/s12630-012-9763-z

[14] Lobato, E.B., Risley 3rd, W.P. and Stoltzfus, D.P. (1997) Intraoperative Management of Distal Tracheal Rupture with Selective Bronchial Intubation. Journal of Clinical Anesthesia, 9, 155-158. http://dx.doi.org/10.1016/S0952-8180(96)00241-3

[15] Daitoku, K., Sakai, T., Yamada, Y., Tsushima, T., Koyoma, M. and Takaya, S. (2002) Succesfully Repaired Traumatic Tracheal Disruption and Cardiac Rupture with Cardiopulmonary Support. The Japanese Journal of Thoracic and Cardiovascular Surgery, 50, 70-73. http://dx.doi.org/10.1007/BF02919668 
Scientific Research Publishing (SCIRP) is one of the largest Open Access journal publishers. It is currently publishing more than 200 open access, online, peer-reviewed journals covering a wide range of academic disciplines. SCIRP serves the worldwide academic communities and contributes to the progress and application of science with its publication.

Other selected journals from SCIRP are listed as below. Submit your manuscript to us via either submit@scirp.org or Online Submission Portal.
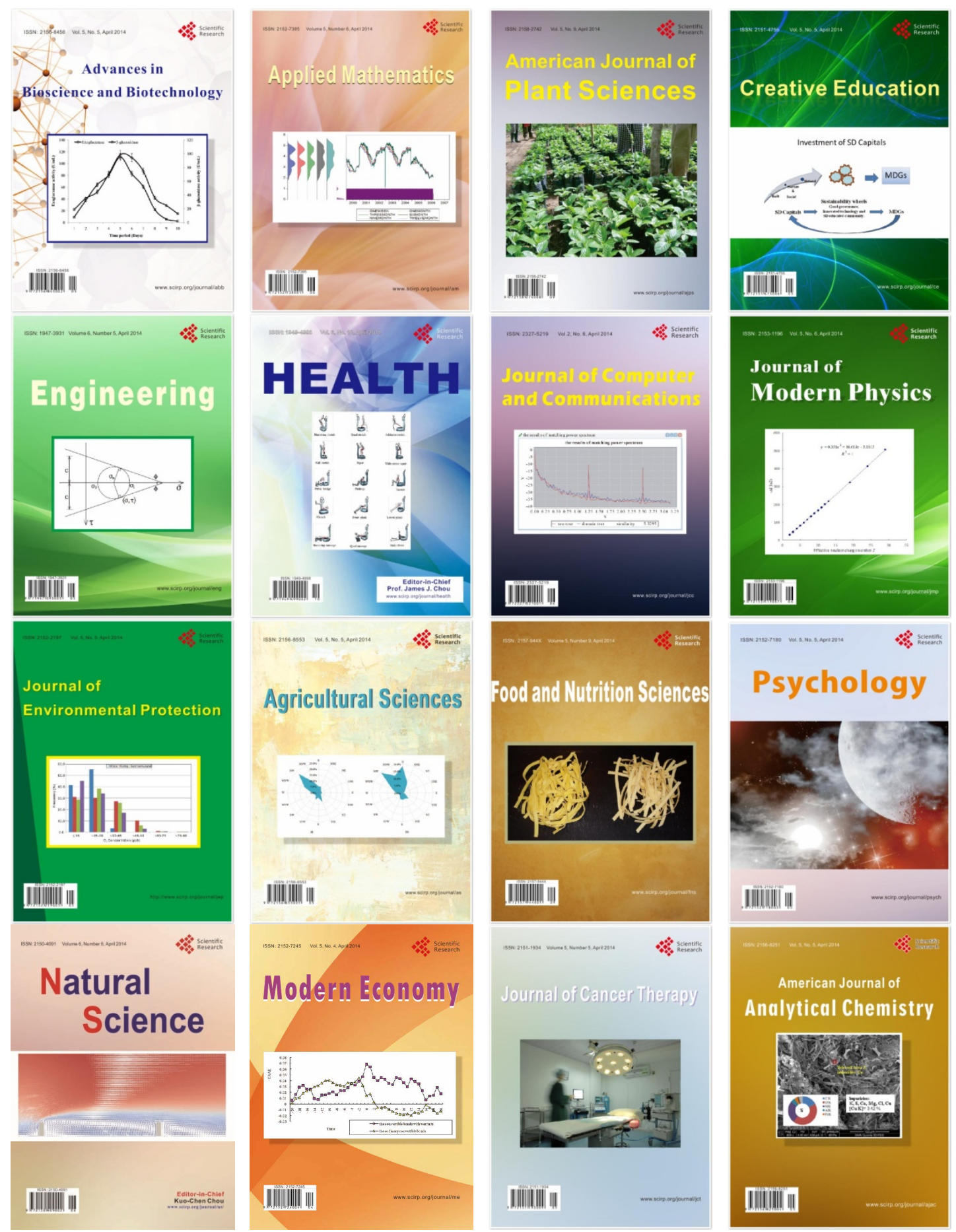